\title{
Playing the Old Tunes: A Fiskean Analysis of Baz Luhrmann's 2013 Cinematic Adaptation of The Great Gatsby
}

\author{
Marjan Khodamoradpour ${ }^{1, a^{*},}$, Alireza Anushiravani ${ }^{2, b}$ \\ ${ }^{1}$ Graduate Student, Department of Foreign Languages, Shiraz University, Iran \\ ${ }^{2}$ Professor, Department of Foreign Languages, Shiraz University, Iran \\ amarjankhodamorad@gmail.com, banushir@shirazu.ac.ir \\ ${ }^{*}$ Corresponding author
}

Keywords: The Great Gatsby, Cinematic Adaptation, Baz Luhrmann, John Fiske, Ideology

\begin{abstract}
Scott Fitzgerald's The Great Gatsby has been adapted many times by different directors. However, the two prominent adaptations standing out throughout history are Jay Clayton's 1974 adaptation as the most sincere rendering of the book, and the recently adapted movie by the Broadway director, Baz Luhrmann. The latter adaptation is important in that it has been accomplished in the age of technology, in 3D format, and at the time of the new readings, i.e. cultural or new historical readings, of the novel. This paper is an endeavor to analyze the movie through John Fiske's theory on media studies. Also, an effort has been made to see whether in this new adaptation, the idea of the new studies of the novel have been shown by the director, or else the movie is a mere representation of struggle for money discussed by the traditional Marxist scholars, metaphorically playing the old tunes.
\end{abstract}

\section{Introduction}

According to John Fiske, Television and visual media, in general, as cultural agents broadcast meaning-laden programs, and they try to control and limit their meanings to a preferred meaning that works in favor of the dominant ideology [1]. He believes that media is determinant, i.e. it aims at developing social control, and in so doing, it acts like the dominant ideology. For him, movie, TV programs, and, in general, media are texts to be read, and these texts are places of struggle for meaning [1]. In order to show how visual media attempts to make the meanings that are in the service of the dominant powers of the society, John Fiske proposes a semiotic analysis of the products by analyzing their signs and codes. To provide a Fiskean analysis of the movie, then, the authors shall adapt the same approach, i.e. analyzing the movie by focusing on four pivotal scenes from the 2013 cinematic adaptation of The Great Gatsby by Baz Luhrmann.

An already encoded reality, according to John Fiske, is what we face, and it is based on the codes of our culture that we can understand reality. Therefore, in any culture, reality is the result of that culture's codes. When this encoded reality is pictured, some technical and representational codes are used in order to make the piece technologically transmittable and capable of producing an acceptable cultural text [1]. Baz Luhrmann, like other directors, makes great use of the social codes such as dress, hair, skin color, facial expressions, etc., and conventions of setting and landscape to constitute the realities of the time. For instance, when for the first time in the movie Daisy Buchanan is shown, reducing the beginning conversation exchanged between Nick and Daisy in the novel, the conventions of the representation of speech as realistic dialogue lead to her asking an overindulgent question (00:07:30), "Do they miss me in Chicago?," which is provided with a pretentious reply by Nick Carraway, as a member of their race [2]. Such a representation of Daisy in the beginning reveals a lot about her character. She has been introduced as a simple-minded woman whose concerns lack any profundity; this is the depiction of women according to the ideological code of patriarchy. Likewise, in the same episode women, Daisy Buchanan and Jordan Baker, are shown lying on the air-filled white couch; Jordan's remark: "been lying on that sofa as far as I could remember" (00: 08:09) implies the ideological views of the patriarchal society that urges women to 
stay home as inactive individuals [2]. The naturalness with which the ideas is shown is indicative of how ideological codes cooperate to organize and coordinate the other codes so that they can create consistent sets of meanings which form the common sense of a society. Therefore, conventional and social codes of the society are the workings of the ideology which are reflected in the text in a way that they are considered natural to the commonsense.

The process of perception, as John Fiske posits, includes a continual uncovering of the levels, since perception is possible when reality, representations and ideology are naturally united. Cultural or semiotic criticism reveals this natural unity as a totally ideological concept and deconstructs it [1]. A semiotic analysis indicates how these multifarious levels of the encoded meaning have been constructed into the movie. The following parts will be the uncovering of some of these encoded meanings by examining the devices that help create them.

\section{Fiskean Analysis of Baz Luhrmann's The Great Gatsby}

Baz Luhrmann's new version of The Great Gatsby has been made in 3D. Through restless camerawork, deep focus techniques and imaginative CGI, he has tried not only to meet the financial needs of the film business and economic obligations, but also to allure the new audiences to gaze at an old literary creation through the stereoscopic screen that differentiates it from the previous kaleidoscopic one. Moreover, according to Steve Chibnall, Baz Luhrmann uses 3D "as a mediated spectatorial process" which matches the tendency of his cinema to "filter ideas, narratives, and even emotions through a web of accumulated artistic creations" [3]. Baz Luhrmann's challenge is to freshen the ideas and ideologies in the most exciting way and to naturalize them for the present time. Therefore, the reality that he attempts to picture is "the hyper-reality made possible by digital technologies, the image electronically airbrushed, edited, and color-enhanced to perfection" [3]. Accordingly, Luhrmann makes great use of the camerawork as a technique by whose help he can encode the ideas and broadcast them as accepted and natural realities, and by decoding some of these encoded realities we could see through the ideologies that are shown in the movie.

Based on what John Fiske argues, the angle and deep focus of the camera are used to give the spectator a complete, ideal view and "sense of omniscience", leading to a total perception of the scene [1]. This sense of omniscience is a source of pleasure for the audience. The camera person has some available choices to give meaning to what is pictured, including: distance, framing, focus, camera placing, angle and lens choice, and movement of the lens or the camera [1].

Throughout the movie, and particularly the four most significant scenes in which Gatsby and the Buchanans meet, the camera distance changes so that the audience's sympathies move away from one character to another. The Buchanans, Daisy and Tom, are mostly shown in mid-shot to close-up, so that the normal distance is kept and their power of dominance is preserved. However, Gatsby is, in most parts, presented in extreme close-ups (ECUs). Throughout the first episode of Gatsby's encounter with Tom, in the short time that Tom comes into the speakeasy and Nick introduces him to Gatsby which is about 45 seconds, there are only three scenes in which ECUs are used (00:44:21, 00:44:25, and 00:44:31) and all of them are utilized only to represent Gatsby [2]. This is an encoded way to show how the individual who is less powerful and not considered as a member of the dominant society can be overwhelmed by close observation, and how he is donated less privacy than those of the upper class. In the same manner, extreme close-ups are used to picture Mayer Wolfshiem; from the very beginning of his picturing (00:40:00) we see him in extreme closeups [2]. There are twelve ECUs for picturing Wolfshiem while he is talking with Nick about Gatsby and business connections in the speakeasy $(00: 42: 40)$, and all of these are a codified way to represent his villainy [2].

John Fiske enumerates two sources of conventions that govern the meanings created by the code of camera distance. The first source is the social code of interpersonal distance, which implies that in western cultures the space about 24 inches $(60 \mathrm{~cm})$ of the individuals is encoded as private. Entering this space is interpreted as either hostile or intimate. ECUs copy this, and are utilized for 
showing the scenes which represent intimacy or hostility, and the meanings they convey is dependent on the other technical and social codes by which they are contextualized, and by the ideological codes they are affected by. The other source is situated in the technical codes which indirectly suggest that seeing from a close viewpoint means seeing better, seeing into the villain, seeing through his words, and thus gaining power over him, the power and the pleasure of "dominant specularity" [1]. These technical and social codes make the ideological encoding of villainy obvious.

In the scene that Tom and Daisy take part in Gatsby's party, as the confrontation of Tom and Gatsby is shown again, ECUs are used to show the difference between the two characters. In the part that Gatsby and Tom sit beside each other, they are depicted in a close up, but when they start their conversation, Gatsby is shown through more ECUs, about 10 times. What is significant about it is that Gatsby is under the total surveillance of the spectator. When the butler informs him of the presence of one of his businessmen, through the extreme close up, we see how, while becoming quite furious, he states that it was not the right time (1:12:12) [2]. By this reaction of Gatsby and the ECU, one becomes sure of the illegality of the business. Similarly, whenever the business of Gatsby is mentioned within the movie or Gatsby is on the phone with one of the connections, his face, shown through an ECU, is serious and nervous, and this is suggestive of the villainous-ness of the character.

Additionally, in the last two scenes in which the main characters assemble, i.e., at the Buchanans's house and after that at the Plaza Hotel, the highest number of ECUs are used to display Gatsby's reactions and vehemence, respectively 10 and 19 times. In these scenes, and by the help of ECUs, we gradually see the total disempowerment of Gatsby through frequent questions of Tom about his being an Oxford man, his business bonds, etc. . The damaging effect of Tom's toughest statements about Gatsby's difference in blood and congenital inferiority can be seen when the camera focuses tightly on Gatsby's face, using an encoded extreme close up for that scene (01:41:50) [2]. Therefore, in Gatsby's case, this technical code implies that seeing him closely is seeing him better; as a matter of fact this is seeing into the character of Gatsby, and thus gaining the pleasure of having power over him, the pleasure that, Fiske believes, comes from "dominant specularity." Such technical and social codes prove the ideological encodings of otherness, villainy, etc. .

However, Tom, as the foil to Gatsby's character, is mostly presented through close-ups or mid-shots, and so the distance between the audience and Tom is kept so that his reactions are not clearly revealed. This also implies that Tom as an authority, and as a member of the upper class of the society cannot be dominated or disempowered, and that he always keeps his predominance over anything intending to endanger his position. In the few ECUs used for showing Tom, compared with the number of times ECUs are used to show Gatsby, we see him still as a firm character; in fact, these encoded techniques are utilized to indicate how, even in the moments that Tom feels threatened to lose his control over the situation or losing Daisy or Myrtle, like the scene when he, accompanied by Nick and Jordan, is on the way to New York in order to go to Plaza Hotel (01:33:17), he has more control over his emotions and is less reactionary [2]. This can confirm the idea that people of the other classes are more willing to lose temper and have less control over their reactions.

On the other hand, the ECUs which represent Daisy are noteworthy in that they show her as an object of gaze, a symbolic being, a person who is at the same time the signifier of power and an object in the hands of Tom and Gatsby to confirm their positions. Daisy is shown in the way that her clothes and jewels are significantly bright and focused. The first time that Daisy is presented in the movie is through an ECU; we first see her diamond ring and then her face (07:13), the angle and the extreme close up work in such a way that her gestures and possessions capture more attention, and thus, are indicative of her symbolic presence [2].

As it has been mentioned, Baz Luhrmann is persuaded that "the close-up is perhaps the most powerful shot that you can create with 3D" [4]. Thus, along with other techniques such as voice 
over, lighting, make-up, etc., camera work plays a great role in the encoding of the notions intentionally ascribed to the characters of the movie to reveal their social position. Luhrmann makes great use of 3D as the "most irreducibly cinematic device," according to Dana Polan, to slake his thirst for excessiveness shown through camerawork in a movie about insatiability of the excess [5].

One of the other devices that directors partake of in order to imply some covert meanings to their audiences is the use of lighting as a significant device. The way an object, a place or even a person is lit in a movie can have significant meanings. For instance, the Buchanan's mansion is highly lit in white light. When their house is exhibited for the first time, the hall is seen in an utterly white light (00:06:41), or as Gatsby shows their house to Daisy from Nick's balcony, the house is glistening with sun shining over it after the rain (00:59:12) [2]. In contrast, Gatsby's mansion is lit in a dim yellow light. This dark and gloomy lit house shows a hostile treatment of Gatsby; everything he possesses is in great contrast to that of the Buchanans. Except for the colorful parties and the scenes in which Daisy is present at his house, the gothic-like mansion of Gatsby is lit with a very dim yellow and grey light. In addition to this, whenever Gatsby is shown on the phone (00:34:39, 01:05:34), talking to the people working for him, or speaking with the bootleggers after the party in which Tom and Daisy participated (1:18:26), he is shown in a dimly lit room [2].

It is noteworthy that as we are getting to the end of the movie, which is concomitant to the fall of the house of Gatsby and his death, the house gradually gets grey and dark, while the domicile of the Buchanans is still shining in white, even at the time of their departure. This technique of lighting helps to indicate indirectly the difference between the characters, as well as their class and their position in society. As members of the upper class who are in high contrast to the other members of the society, the Buchanans are always shown in glistening, white lit places, while Gatsby, as an inferior to them is positioned in colorful or dimly lit places. Consequently, one can say that the use of lighting in modern movies is not just a way to brighten the scenes so that the camera can shoot the movie, but rather, lighting can add significance to places, objects and people, and this is what Baz Luhrmann has accomplished in his adaptation of The Great Gatsby.

Yet another important device at the director's disposal to add meaning to the scenes is music and how it can add emotional intensity to the movie. Music is among the very crucial elements in the movie by whose help the emotions are taken to specific directions and are dissolved. The music which link the scene that indicates Gatsby's mansion starts in a minor key, and as it moves to the Buchanans' house, it changes to a major (00:05:32) [2]. This contrast between minor and major keys is indicative of the true nature of the characters who are either the villains or the heroes. In most of the scenes when the figure of Gatsby is shown, the music is in minor keys, for example, in the scene that he is alone in the jungle waiting for Nick to come back (00:49:16), the one at Nick's house awaiting Daisy (00:52:43), the scenes that he is shown in close ups and ECUs $(1: 05: 35,1: 06: 52,1: 27: 23,1: 28: 23)$, and in the most revealing scene at the hotel $(1: 42: 06)$ [2]. This way of showing Gatsby, accompanied by minor key music is totally contrary to Tom whose appearance is concomitant to major key pieces of music $(1: 43: 13,1: 54: 26)$ [2]. Therefore, the director takes advantage of music to highlight the characteristics of heroism and villainy in his work according to the dominant ideologies.

Another important factor in determining the hidden meanings of a work is the way different actors and actresses have been cast for their roles. Fiske believes that different actors can have different meanings for the audiences when they are chosen to play a special character. Each actor or actress cast to play a role in a movie is a real individual whose appearance has been encoded by social codes. However, it should be kept in mind that these characters are media people, existing intertextually for the viewer, and their meanings are intertextual as well. They carry both the remaining of the meanings of the roles they have played before in their acting careers, and meanings from other texts like criticisms, fan magazines, and showbiz gossip columns. Therefore, in this part, it is noted that these aspects of meaning are very significant in the code of casting, and they are inevitably important in the casting of the characters whose ideologies are dominant throughout the work [1]. Baz Luhrmann's 2013 The Great Gatsby stars Leonardo DiCaprio, Tobey Mcguire, Carey 
Mulligan, and Joe Edgarten, each having a background of artistic works with them which affects the spectators.

Playing the role of Jay Gatsby, Leonardo DiCaprio reminds the audience of his performances as Jack Dowson in Titanic and Romeo Montague in Romeo and Juliet. Most remembered for the character of Jack Dowson, DiCaprio is reputed as an iconic character of a faithful lover with a humble background chasing an unfulfilled love. Chris Lough, in a pedantic review of DiCaprio's roles in different movies, notes that Gatsby is an alternate for Jack Dowson who finds love with Daisy, who is like Rose of Titanic in many aspects, and his fate and his unfulfilled love is the same as that of Jack's [6]. Characters, thus, are not mere representations of individuals acting in the movie; they have codes of ideology, and they present some ideological values. The tanned face and the attractive appearance of DiCaprio, along with his popularity has made him a character whose performance in the movie, according to many critics, has guaranteed the success of the movie in the box office. For example, Rafer Guzman of Newsday extolled DiCaprio's performance as "a tremendous, hard-won" one, and Matt Zoller Seitz depicted his performance as "The movie's greatest and simplest special effect," and called it "an iconic performance" [7, 8]. Additionally, Nick Pinkerton states that "Dicaprio has allowed himself to be radiant again here ... The self-invented Gatsby is a palimpsest; DiCaprio's delicate, transparent performance allows us glimpses of the erased character [of DiCaprio's previous roles]" [9]. As with the character of Jay Gatsby, it is obvious that ambitiousness is not the only prerequisite for gaining one's goals. Dicaprio's different appearance and skin color, his gestures, etc., as well as his role as someone in opposition with the dominant ideologies, whose representative is Tom, all imply his removal from the system.

Carey Mulligan's roles as Kitty Bennette in Pride \& Prejudice (2005), Ada Clare in the TV series, Bleak House (2005), and Isabella Thorpe in Northanger Abbey (2007) have proved her as an impressive character of adaptations. In The Great Gatsby, she takes the role of Daisy Buchanan, and she has been successful in creating the symbolic presence of Daisy within the movie from many a different critic's point of view. According to David Denby "Mulligan makes it clear how much Daisy is a projection of male fantasy. The men struggle to possess her; she doesn't possess herself" [10].

Moreover, Tobey Mcguire is most remembered for his role as Peter Parker / Spider-Man in Spider-Man film trilogy (2002-2007). Mcguire has also participated in many films with DiCaprio and his performance and friendship with Gatsby in the movie reminds the readers of the pair's previous roles in many works such as "Parenthood," "This Boy's Life"[11].

In addition to these characters, Luhrmann has given the role of Mayer Wolfsheim to the Indian Bollywood actor Amitabh Bachchan, by which, as Alan Stone posits, simultaneously eliminates any traces of anti-Semitism and makes the film more commercially appealing to one of the most significant economies of the world [12].

John Fiske calls casting a conventional representational code, and appearance a social code, but in his idea, the two differ only in intentions and lucidity. He posits that "people's appearance in "real life" is already encoded: in so far as we make sense of people by their appearance we do so according to conventional codes in our culture" [1]. Therefore, the casting director makes great use of these codes knowingly and more stereotypically. What makes DiCaprio's Gatsby an outstanding one compared to the previous adaptations, as David Denby puts it, is his praising stare and the charming appearance of him [10]. Enumerating DiCaprio's preferences, he notes that "DiCaprio, thirty-eight, still has a golden glow: swept-back blond hair, glittering blue-green eyes, and smooth tawny skin. The slender, cat-faced boy of "Titanic" now looks solid and substantial, and he speaks with a dominating voice" [10]. Furthermore, Mulligan's role as Daisy has made it a symbolic construct; Steve Chibnall stresses that she is "a projection of male romantic fantasy" because of her faun-like face [3].

According to what John Fiske explains about casting, it is revealed that the director makes use of it to picture everything to the favor of the dominant classes. For example, on the subject of violence, as he mentions, Gerbner explains that heroes and villains equally use violence and initiate it, but he 
notes that heroes are successful in their violence, while villains are not [1]. The violence is significantly shown by the director in the movie as Tom and Gatsby confront each other at the Plaza Hotel. Tom's violence is shown through his contemptuous discourse and this leads to Gatsby's violent physical reaction toward Tom (01:41:52) [2]. This scene shows how Tom is conscious of his ways to degrade Gatsby, and how Gatsby is affected by him and his ideologies, consequently flabbergasting the others by his uncontrolled wrath.

Using Gerbner's findings helps to theorize that the Buchanans are the socially central types who represent the dominant ideology and typify the heroes, whereas Gatsby, as the member of the deviant or subordinate subculture who thence embodies the dominant ideology less completely, and even follows the ideologies that oppose it, is the villain. The textual opposition between Tom and Gatsby, and the violence by which this opposition is dramatized become metaphors for power relationships in society and material practice through which the dominant ideology works. The prime example of this is the scene at Plaza Hotel in which Gatsby loses his temper as the result of Tom's words about the impossibility of his acceptance as one of their class because of his difference in blood (01:41:54) [2].

It is also significant that the villain, as John Fiske describes him, is not American and shows hints of it; Gatsby's accent and speech is British, he has tanned skin and at times wears fancy clothes, such as the pink suit at the Buchanans' house and the Plaza Hotel, to which Tom also refers (01:35:12), that makes him different from the others [2]. But the Buchanans are both clearly upper class, white Americans, at home among the people of their class like Jordan Baker and Nick Carraway. Although Daisy falls in love with Gatsby, she finally changes her mind and remains with Tom. This shows how ideologies are implied, and as Gerbner's work reveals the villain, here Gatsby,'s chances to survive are pretty slim. However, it is noteworthy that in the movie, Baz Luhrmann takes side with Gatsby as the character who has been faithful to his dreams and his love and does not go seriously through the idea of his job as a bootlegger. Despite this fact, he implies some aspects of his villainy as mentioned above. Mayer Wolfshiem is also another villain shown in the movie whose villainy is depicted through the differences in accent, skin color and appearance.

Therefore, according to what has been said and John Fiske's ideas, it has now become clear that technical codes of television transfer, and in some cases unify with, the social codes working to generate meanings and embody the ideological codes.

Another important element in producing a film is the matter of setting and costume. The hero/ine's house, according to John Fiske, is bigger than that of the villain/ess; their house is humanized, i.e. it is made attractive by flowers and drapes. On the other hand, the architecture of the villaine/ness's house is bizarre, having hard lines and sharp angles [1]. Baz Luhrmann's movie reproduces the two mansions distinctively. For example, the long shot that introduces us to Tom's house shows a massive mansion located in a green field (00:05:39) [2]. Not only are the walls all white, but also the walls inside, as well as the curtains and the dress of the women are all white, and this whiteness has been projected faithfully according to the novel's descriptions. When Tom hurries towards Nick and pushes him through the brown door into the room in which white curtains fly in the air, this total whiteness is presented in its complete sense. In sharp contrast to this whiteness that dominates the descriptions of Tom and Daisy's house, we have a certain darkness or a state of being colored surrounding Gatsby's mansion (01:00:15) [2]. No part of his house seems to be purely white. The walls outside seem to be portrayed as grey and cream with blue window glasses, and the walls inside are either grey or brown. Besides, the Buchanans' residence is located in a wide field and its flatness is eye catching, while Gatsby's mansion is situated in a less wide ground, exactly at the opposite side of the Buchanans, with sharp-edged domes, bizarre and gothiclike architecture. This discrepancy is indicative of Gatsby's difference in taste and position from that of the dominant class. This also illustrates the racial difference between Tom and Jay Gatsby which is significant because it is what forces Gatsby to partake of other sources of distinction between them as a last resort to win Daisy over. As Philip Mcgowan expresses "Tom dominates a land of static whiteness," and this is clearly resonated in the movie [13]. In addition, another 
important indication of Luhrmann's observant eye with regards to the descriptions of places is the fact that Daisy and Tom's mansion is almost always shown in daylight, whereas Gatsby's mansion is always described in the night and in gloomy atmosphere.

The other point of difference between the villains and the heroes, in John Fiske's idea, is costume. He believes that, compared to the hero's outfit and costume, the villain mostly wears less tasteful clothes that place him among the inferior members of the society. Within the movie, we see Gatsby wearing colorful outfits and even fancy clothes like the pink suit (again faithful descriptions of the novel) that Tom also makes fun of him for, by saying "a man in the pink suit went to Oxford!" (01:35:12) [2]. Therefore, such physical differences revealed by the social codes of setting and costume also bear the ideological codes of "class, heroism and villainy, morality, and attractiveness" [1]. Consequently, what Luhrmann benefits from is the use of material social codes of houses and clothes and the differences between the two classes, so that the ideological codes are naturalized through them.

It should be noted that some ideological codes are more clearly expressed compared with others: John Fiske refers to the codes of heroism, villainy, and attractiveness as working explicitly [1]. Under these codes, however, the codes of class, race, and morality work more implicitly: what they ideologically do is to naturalize the mutual relation of the lower-class, non- American with the tasteless, less moral, and thus villainous. Gatsby's bragging about his braveries at war, his education and his possessions, his less controlled behavior, different accent, tasteless clothes and house, and amoral job as a bootlegger, shown very explicitly by the director, all work to show his different class, race, and morality from that of the upper class. Conversely, the Buchanans as the upper-class white Americans have conservative behavior, they are more attractive and tasteful, and they adapt to the dominant ideas of morality. This replacement of morality onto class is a feature that the movie takes advantage of in order to indicate different aspects of their culture: it is through villainous acts such as bootlegging that Gatsby has gained the chance of accumulating huge amounts of money whereby he can appear in the world of the Buchanans and the upper-class society.

Setting and Costume work in close affinity with make-up. Make-up is also important in a movie simply because a lot can change about a character's appearance, and this change can have significant meanings in the context of the film. Similarly, based on John Fiske's theory, mixing the ideological codes of morality, attractiveness, and heroism/villainy, and condensing them into a material social code, can be viewed in an apparently unimportant thing such as lipstick [1]. Daisy has some signs that differentiate her from the other women in the movie, e.g. she is blonde, white American, pretty, and more moral than the others such as Myrtle. It should be explained that the reason for Daisy's relationship with Gatsby is love; and as an upper-class, she is not permitted to marry a man of the lower class with no properties, so when she is assured of Gatsby's position, she accepts him. But, Myrtle's relationship with Tom is only based on money, thence it is totally amoral. Besides, Jordan Baker has some relations which are merely flirtations. Therefore, Daisy is seen as less amoral and more attractive than any other woman. Her hair color and style, her whiteness which is more emphasized through make up, and her glistening lips that are made up to be seen fuller and more attractive all work to show that as an upper-class she is different. Moreover, it can be predicted that she will remain on the side of the dominant ideology of which Tom as the representative. According to John Fiske, the ideology of lipstick might seem to be a "stretched concept, but it is in the aggregate of apparently insignificant encodings that ideology works most effectively" [1].

The following element is what brings movies alive, i.e. the action of a movie which sets it in motion. What characters do in a movie is sometimes the only defining factor that motivates spectators to go on watching; however, knowing what lies beneath these actions is also believed to give audiences feelings of domination over the ideas embedded within the work, and that is why John Fiske proposes that actions must also be analyzed. John Fiske believes that the heroes and the villains have many significant similarities and differences in their actions [1]. The first commonality that he mentions for the extract he reviews also works within this movie. He argues that one 
commonality is that women are seen to be prettying themselves, and men planning, almost all of the times [1]. Within the movie, The Great Gatsby, we see how Gatsby has been planning, literally most of his life, to win Daisy over; first he plans to be wealthy enough to win Daisy's heart, then he buys a mansion and holds extravagant parties so that she attends them once, and when Daisy doesn't show up, he tries to come up with a connection, Nick Carraway. On the other hand, when Tom becomes aware of Gatsby's threat, he plans to remove him, so he investigates into Gatsby's past and the source of his excessive amounts of money whereby he can reveal his villainous acts and retain Daisy. Therefore, such depictions of men as instigators of action, based on Goffman's ideas, "naturalizes the man's executive role" and "the woman's role as object of the male gaze" [1]. The fact is that this is an accepted truth to Tom, Daisy and Gatsby, and even Jordan Baker and Nick Carraway. The way that they are presented proves it to be unquestionable in the narrative, and puts it into the realm of everyday common sense in which the narrative is enacted. The other shared action to both the hero and the villain is the gaining and keeping of a precious possession, here Daisy, as an instigator of their action; this also is a part of the ideological framework through which that conflict is viewed and perceived.

A difference between their actions is that of cooperation and closeness versus loneliness. At the beginning of the movie Tom and Daisy Buchanan are seen as a close, ideal couple, and as Daisy states she "is paralyzed with happiness" of that life (00:07:047) [2]. Although their relationship becomes problematic with Gatsby's entrance, at the end we see them even closer, standing beside each other leaving their mansion (02:04:22) [2]. However, Gatsby is alone from the first scene that he is shown, he is killed when he is swimming in the pool alone, and it is noteworthy that nobody attends his funeral. Therefore, this is another bearer of the dominant ideology that people of the same class and race remain beside one another and those of other races must be alone or must be removed if they try to enter their life and ruin this discipline.

Having talked about how actions can have deeper meanings, it's time we now turned to what enriches the action of a movie, and that is the dialogues exchanged between the characters. Dialogue is also utilized to affect the spectator's sympathy. The dialogue of the villain, as John Fiske mentions, "is restricted to nefarious plans," whereas the hero and heroine's dialogue is indicative of their "co-operative relationship" [1]. The dialogues of Tom are most of the time filled with the dominant ideologies of racial and class distinction. One example is that in the first scene at Tom and Daisy's house, while they are eating dinner with Nick and Jordan, Tom posits his ideas on the subject of civilization (00:09:18) [2]. The idea is that the dominant race is threatened by other races, referring to the black servants. Another example is the scene at the Plaza Hotel; when talking about the importance of family institution, Tom refers to the menace of the intermarriage between the blacks and whites (01:36:30) [2]. There are many other examples of Tom's racially discriminated and class-based dialogues within the novel which have also been emphatically reflected within the movie. In contrast, most of Gatsby's dialogues exist to show off his possessions, and his fabricated background and education, or on the notions like love, which is not in line with the dominant ideologies of the time. Thus, dialogue, i.e., scripted speech, which is considered by John Fiske as a technical code is another means that, in collaboration with other social and technical codes, help the director to emphasize on some particular ideological notions and codes which will be analyzed in the following parts.

The above mentioned codes and the visual codes that broadcast them to the audience are both integral parts of the ideological codes that they themselves bear. If the same ideological practice is to be adopted in the decoding as in the encoding, we will be given the position of a "white, male, middle-class American (or westerner) of conventional morality" [1]. According to John Fiske,

the reading position is the social point at which the mix of televisual, social, and ideological codes comes together to make coherent, unified sense: in making sense of the program in this way we are indulging in an ideological practice ourselves, we are maintaining and 
legitimating the dominant ideology, and our reward for this is the easy pleasure of the recognition of the familiar and of its adequacy. [1]

Based on what Louis Althusser posits, texts make us 'reading subjects,' and in capitalist societies, such construction of subjects-in-ideology is the major ideological practice. This ideological practice in the movie is working at its hardest in the scenes in which the Buchanans and Gatsby are present. The first scene, at the Buchanans' house, reflects the couple's ideas, as the dominant race, on the subject of race. Tom's dialogue reflects that he belongs to the white hegemony, and he presents the dominant racial ideologies about the notion of civilization. He expresses his class's fear of the dominance of the black race that would consequently result in the intermarriage between the blacks and whites (00:09:18) [2]. Such an argument is also stressed at the episode in the Plaza Hotel, while Tom is talking about Gatsby and his race (01:36:30) [2].

Another dominant ideology is related to the role of the women in that patriarchal society. In the same scene at the Buchanan's mansion, when Tom finishes his dialogue on the subjects of race and civilization, Daisy claims that Tom always "reads deep books with long words in them" and her simple-minded statement that they have to beat those other races down, while grinning, indicates her inability to understand or use complicated subjects and language, and the feminine tendency to perceive everything through a domestic discourse. Another evidence for this is the Town Tattle magazine which is first seen in the hands of Jordan Baker and then at Myrtle's house, showing the interests of women in superficial subject matters. Conversely, men are shown as being involved with profound matters, reading scientific books and journals or even writing. We see Tom referring to the book The Rise of the Colored Empires (00:09:20), Gatsby's library is shown to be filled with various kinds of books, Nick buys and writes books on economics, as Tom says to Myrtle (00:16:38), whereas what all women do is to engage in less serious matters [2].

In addition to these two ideological codes in the movie, according to Anett Koch, women have been represented as objects of male gaze, which communicates patriarchal power structures [14]. Therefore, the term 'male gaze' implies the kind of look which is commanding, possessing, and objectifying. In this regard, women become objects of the scopophilic male gaze, giving men a sense of power. It is also depicted in the movie that in the patriarchal society, men used to objectify women by paying money for them and purchasing them. Tom pays money to Myrtle to be with him for the day; he purchases an overpriced string of pearl for Daisy so that he can marry her and show off his power. This scene has been emphasized by adding special effects and ECUs when the necklace is displayed (00:46:27) [2]. Consequently, jewelry and money are also at the service of another ideology. As we have seen, the gaining and the preserving of wealth has been a major motor of the narrative, and jewelry works as its material signifier. Ideological codes converge in the use of jewelry in the movie: they are the codes of gender, class and power. It is used rather as a sign of power and class, and of aesthetic taste.

Based on what John Fiske says, the aesthetic sense or good taste is utilized as a naturalizing agent and bearer of class distinction [1]. Gatsby's house and outfit, in comparison to the Buchanans', are shown as tastelessly colorful and fanciful. The function of aesthetics in our society, as Pierre Bourdieu posits, is to make "class-based and culture-specific differences of taste appear universal and therefore natural" [1]. The taste of the Buchanans as the representative of the dominant classes is naturalized by the aesthetic theory which puts the taste's stem in class origin. Thus, it is revealed that Gatsby, as a member of the lower class, cannot only cling to money to climb up the class ladder, and since his taste is that of the lower class, it is an impossible affair for him to become a dominant class.

The meaning of jewelry in the code of gender is obvious. The pearl string is the means by which Tom buys Daisy as a patriarchal commodity, and Daisy's wearing it is the sign of her possession by Tom, and it reveals the economic and social status of both of them. John Fiske believes that in the code of gender, no class difference exists between the hero/ine and villain/ess: there are the same economics of patriarchy for all classes, making it appear universal and natural that man provides his woman with [1]. 
Such an analysis has not only revealed the subtlety of meanings encoded in what has usually been considered as superficial, but it also suggests that this complexity and intricacy has a strong effect on the audience. Therefore, according to what has been discussed above, it is inferred that a wide range of codes unite in order to make a coherent set of meanings that work to preserve, justify, and naturalize the dominant ideology of patriarchal capitalism, whose ideological effect seems to be irresistible. Thence, concerning John Fiske's theory, this demonstrates that visual media is both complicated and deeply filled with ideology.

As both director and screen writer, Baz Luhrmann can be considered as the auteur, i.e. the director as the primary creative force, according to Andrew Sarris, who implements a distinguished style and certain thematic and visual elements to the movie [15]. Therefore, Luhrmann has a great role in the reading of the novel from which the movie has been adapted. In this reading of the novel, as it is apparent, the movie has been revolving around a Marxist point of view.

In expressing the personal or political reasons (other than financial ones) for creating an adaptation of Fitzgerald's The Great Gatsby in 2013, Baz Luhrmann referred to the relevance of the story in all times regarding the corruption of morality and its consequences. Luhrmann augmented that the particularity of the story's relevance to today's world is in its anticipation of the crash menacing in 1929. He asserts that

The 20s was a time, because of the shared national hypocrisy of prohibition (people were railing against alcohol one minute and demanding wine at their table the next), that a slightly rubbery morality was allowed to flourish; there was confusion in the national moral dials, so to speak. 1920s New York City was flush with money and booze, the stocks went ever higher, and skyscrapers vaulted to new peaks, and seemed that mankind could only go up. [15]

Therefore, based on what Baz Luhrmann stated, Fitzgerald's representation of the moral corruptions in the society and its crashing down, reveal much about today's world. Luhrmann refers to 9/11 as the event from which point moral corruption increased. Also, the global financial break down of 2008 caused our world collapse down [15]. He counts these as the best reasons to show the pertinence of the story of Gatsby to our time in addition to its financial matters.

Now that it has been analyzed from the viewpoint of John Fisk's theory, it is noteworthy to maintain that the movie, as an adaptation is rather a failure regarding its cultural reading. According to the new readings of the novel, the base of struggle in the novel is not just related to who has got the largest amount of money. Rather, as cultural readings of the text would lead us to believe, other issues than money are used in determining the dominant class and ideology. Nevertheless, the movie only focuses on the monetary value as the capital needed to be a member of the upper class, and it fails to take into consideration that Gatsby becomes as rich as Tom, and that money is no longer the defining factor.

Therefore, in the movie, money has become the center and the only means to climbing up the class ladder; this approach is clearly shown in the scene at the Plaza Hotel. Regarding the fact that the dialogues used in the movie are mostly the same as the ones in the novel, and that the movie observes faithfulness in this aspect, in the scene at the Plaza Hotel one part has been added which sums up the main ideas of struggle for money and substantiates them. When Gatsby is interrogated by Tom about his job and his financial sources and he faces Tom's remarks on these subjects, he states that "The only respectable thing about you, old sport, is your money. Your money, that's all. I have just as much as you, and that means we are equal." (Emphasis Mine, 01:41:21) [2]. This added dialogue shows how the director has been affected by the idea that only money matters, and therefore he has limited the other ideas and ideologies within his work. This is also the evidence to show how shallow Baz Luhrmann's interpretation and perception of the story has been, and how he has neglected the culture-based conflicts exemplified in the struggle to win Daisy over. Luhrmann's use of all the technology and the aforementioned kinds of codes have been concentrated on the 
merely Marxist reading of the story, and his main purpose has been the entertainment matters, that's why many confirm that his work is not a profound reading of the story of Fitzgerald.

In order to draw the interests of various groups with different and even conflicting tastes in a society, texts must be, according to Eco, "open." By open texts, he means the ones that do not try to close off alternative meanings and limit their concentration to one easily accessible meaning, but rather the texts which are open to a variety and complex sets of readings that cannot be limited [1]. Therefore, open texts resist closure, whether the closure exerted by the dominant ideology through discursive structure or by the author or director's exerting authority over the audience. However, as a closed text, Baz Luhrmann's The Great Gatsby denies the possibility of other meanings.

\section{Conclusion}

In this paper, an effort was made to analyze Baz Luhrmann's movie from different aspects, including actions, dialogues, setting and costume, etc., to show how the director has partaken of all his resources to create a visually appealing product. In the final part, however, the relationship between the movie and the text was analyzed, and we came to see how Baz Luhrmann has only provided the audiences with a Marxist, money-based reading of Fitzgerald's text, i.e. a reading that doesn't take into consideration the struggles which have come to light with help of new readings of the novel. Luhrmann shows the struggle of these characters to be over nothing but the question of who has more money, and this limited reading is what has led many critics to claiming that his adaptation has been an unsuccessful one.

\section{References}

[1] John Fiske, Television culture: popular pleasures and politics, Taylor \& Francis e- Library, New York, 2001.

[2] B. Luhrmann, C. Martin, D. Wick, L. Fisher, C. Knapman, (Producers), B. Luhrmann, (Director). (2013). The Great Gatsby [Motion picture]. Australia: A Warner Bros. Pictures.

[3] Chibnall, Steve, Film review If You Build It, She Will Come: An Appreciation of Baz Luhrmann's The Great Gatsby (2013), Adaptation. 7:1 (2014) 94-97.

[4] Information on http://www.hollywoodreporter.com.

[5] Dana Polan, The Great American Novel as Pop-Up Book: Baz Luhrmann's The Great Gatsby, Adaptation. 6:3 (2013) 397-399.

[6] Information on http://www.tor.com.

[7] R. Guzman, (2013, May 6). 'The Great Gatsby' review: A good 'Gatsby', but a great Leonardo DiCaprio. Newsday. Retrieved from http://www. newsday.com/entertainment/movies/the-greatgatsby-review-a-good-gatsby-but-a-great-leonardo-dicaprio-1.5207150.

[8] Zoller Seitz, M. (2013, May 8). The Great Gatsby. Roger Ebert. Retrieved from http://www.rogerebert.com/reviews/the-great-gatsby-2013.

[9] Nick Pinkerton, The Great Gatsby, Sight \& Sound. 23.7 (2013) 66-67.

[10] D. Denby, (2013, May 5). All that Jazz. The New Yorker. Retrieved from http://www. newyorker.com/magazine/2013/05/13/all-that-jazz-3.

[11] Information on http://www.bfi.org.uk.

[12] Alan A. Stone, The Greater Gatsby, Boston Review. 38:4 (2013) 76-79.

[13] Philip McGowan, The American Carnival of The Great Gatsby, in: Harold Bloom (Ed.), Bloom's Modern Critical Interpretations, Infobase Publishing, New York, 2010, pp. 145-156.

[14] Anett Koch, The Visual Aesthetics of Baz Luhrmann's Red Curtain Cinema, Intensifying the Experience and Exposing the Artifice in William Shakespeare's Romeo + Juliet, Moulin Rouge and The Great Gatsby, M.A. thesis, University of Mannheim, Mannheim, Germany, 2014.

[15] Luhrmann, Baz, Baz Luhrmann's Gatsby Journal, Warner Bros Home Entertainment, California, 2013. 